\title{
Key Lessons and Impact of the Growing Healthy mHealth Program on Milk Feeding, Timing of Introduction of Solids, and Infant Growth: Quasi-Experimental Study
}

Rachel A Laws ${ }^{1,2}$, BSc (Nutrition), MSc (Nutrition \& Diet), PhD; Elizabeth A Denney-Wilson ${ }^{2,3,4}$, BN, MPH, PhD; Sarah Taki ${ }^{2,5}$, MPH; Catherine G Russell ${ }^{2,5}$, BSc, BHSc, PhD; Miaobing Zheng ${ }^{1,2}$, BSc (Hons), PhD; Eloise-Kate Litterbach $^{1,2}$, BHSc (Hons); Kok-Leong Ong ${ }^{6}$, BASc, PhD; Sharyn J Lymer ${ }^{2,7}$, BPthy, BA, MSc, PhD; Rosalind Elliott $^{2,5}, \mathrm{RN}, \mathrm{PhD}$; Karen J Campbel1 ${ }^{1,2}$, BSc, MPH, PhD

\footnotetext{
${ }_{1}^{1}$ Institute for Physical Activity and Nutrition, School of Exercise and Nutrition Sciences, Deakin University, Geelong, Australia

${ }^{2}$ Centre for Obesity Management and Prevention Research Excellence in Primary Health Care, Sydney, Australia

${ }^{3}$ School of Nursing, University of Sydney, Sydney, Australia

${ }^{4}$ Sydney Local Health District, Sydney, Australia

${ }^{5}$ Faculty of Health, University of Technology Sydney, Sydney, Australia

${ }^{6}$ La Trobe Analytics Lab, La Trobe University, Melbourne, Australia

${ }^{7}$ Faculty of Pharmacy, University of Sydney, Sydney, Australia
}

Corresponding Author:

Rachel A Laws, BSc (Nutrition), MSc (Nutrition \& Diet), PhD

Institute for Physical Activity and Nutrition

School of Exercise and Nutrition Sciences

Deakin University

Locked Bag 20000

Geelong, 3220

Australia

Phone: 6192445574

Fax: 6192446017

Email: r.laws@deakin.edu.au

\section{Abstract}

Background: The first year of life is an important window to initiate healthy infant feeding practices to promote healthy growth. Interventions delivered by mobile phone (mHealth) provide a novel approach for reaching parents; however, little is known about the effectiveness of mHealth for child obesity prevention.

Objective: The objective of this study was to determine the feasibility and effectiveness of an mHealth obesity prevention intervention in terms of reach, acceptability, and impact on key infant feeding outcomes.

Methods: A quasi-experimental study was conducted with an mHealth intervention group (Growing healthy) and a nonrandomized comparison group (Baby's First Food). The intervention group received access to a free app and website containing information on infant feeding, sleep and settling, and general support for parents with infants aged 0 to 9 months. App-generated notifications directed parents to age-and feeding-specific content within the app. Both groups completed Web-based surveys when infants were less than 3 months old (T1), at 6 months of age (T2), and 9 months of age (T3). Survival analysis was used to examine the duration of any breastfeeding and formula introduction, and cox proportional hazard regression was performed to examine the hazard ratio for ceasing breast feeding between the two groups. Multivariate logistic regression with adjustment for a range of child and parental factors was used to compare the exclusive breastfeeding, formula feeding behaviors, and timing of solid introduction between the 2 groups. Mixed effect polynomial regression models were performed to examine the group differences in growth trajectory from birth to T3.

Results: A total of 909 parents initiated the enrollment process, and a final sample of 645 parents (Growing healthy=301, Baby's First Food=344) met the eligibility criteria. Most mothers were Australian born and just under half had completed a university education. Retention of participants was high $(80.3 \%, 518 / 645)$ in both groups. Most parents $(226 / 260,86.9 \%)$ downloaded and used the app; however, usage declined over time. There was a high level of satisfaction with the program, with 86.1\% (143/166) 
reporting that they trusted the information in the app and 84.6\% (170/201) claiming that they would recommend it to a friend. However, some technical problems were encountered with just over a quarter of parents reporting that the app failed to work at times. There were no significant differences between groups in any of the target behaviors. Growth trajectories also did not differ between the 2 groups.

Conclusions: An mHealth intervention using a smartphone app to promote healthy infant feeding behaviors is a feasible and acceptable mode for delivering obesity prevention intervention to parents; however, app usage declined over time. Learnings from this study will be used to further enhance the program so as to improve its potential for changing infant feeding behaviors.

(JMIR Mhealth Uhealth 2018;6(4):e78) doi: 10.2196/mhealth.9040

\section{KEYWORDS}

mHealth; obesity prevention; infancy; parents; breastfeeding; complementary feeding; formula feeding

\section{Introduction}

The World Health Organization has identified the prevention of obesity in early life as a key priority [1]. Children are becoming overweight at a relatively young age, with $22.8 \%$ of Australian children aged 2 to 4 years already overweight or obese [2] with substantial health and economic consequences [3]. Infants who are at the highest end of the distribution for body mass index (BMI) or who grow rapidly during infancy are at increased risk of subsequent obesity in both childhood and adulthood $[4,5]$.

Infant feeding practices, including the duration of breastfeeding, formula feeding practices [6-8], when solid food is introduced [9], and whether a baby is predominantly fed on a schedule or according to their hunger and satiety cues, are associated with rapid weight gain $[10,11]$. Australian and international infant feeding guidelines recommend that infants are exclusively breastfed to around 6 months of age when solid foods should be introduced and that breastfeeding continue for 12 months or longer $[12,13]$. However, Australian data indicate that only $15 \%$ of infants are exclusively breastfed until 6 months of age, with $40 \%$ of infants having at least some formula by 1 month of age [14]. Similar numbers are found in the United States where national rates of exclusive breastfeeding at 6 months are $22 \%$ [15]. Furthermore, over a quarter (28.4\%) of Australian infants are introduced to solids by 4 months of age and over half (56.2\%) by 5 months [14]. This clearly highlights the need for interventions to promote recommended infant feeding practices.

There is increasing evidence that children from low socioeconomic backgrounds have higher rates of overweight and obesity [16], and socioeconomic disparities begin early in life [17]. A recent review found that a strong socioeconomic gradient exists for the majority of early life risk factors for child obesity [18], suggesting that early intervention is critical in reducing socioeconomic inequalities in overweight and obesity in childhood and related chronic diseases in adulthood. However, socioeconomically disadvantaged families are often more difficult to reach and may be less likely to participate in traditional programs that support healthy behaviors [19].

One emerging and promising area to facilitate parent engagement at a low cost is the provision of support for parents through electronic media such as the Internet or smartphones. Smartphone ownership is increasing worldwide, with Australians having the highest rate (93\%) of access to smartphones [20].
Women aged 18 to 49 years (many of whom are mothers) spend on average 21 hours a week on their smartphone [21]. Well-designed smartphone apps can provide around the clock high-quality information, as well as personalized and tailored support at low cost [22]. Evidence suggests that although parents increasingly rely on the Internet for information on infant feeding and care [23-27], less research has been conducted on the use of smartphone apps in the postpartum period. One study reported that low-income women commonly use apps during pregnancy, but not in the postpartum period because of the limited availability of high-quality apps, creating a postpartum app gap [28]. This is in line with our own research where we found that infant feeding apps available in Australia are generally of low quality [29].

Early research on the effectiveness of mHealth interventions in changing health behavior is promising [30-32]; however, this is the first study, to our knowledge, to investigate the effectiveness of mHealth interventions in influencing parents' infant feeding behaviors. The Growing healthy $(\mathrm{GH})$ study aimed to explore the feasibility of providing information and support to parents for healthy infant feeding practices using an mHealth program. This paper reports on the effectiveness of GH in terms of reach, use, acceptability, and several key infant feeding outcomes including the promotion of exclusive or continued breastfeeding, best practice formula feeding, timing of introduction of solids, and infant growth.

\section{Methods}

The study utilized a quasi-experimental design with an mHealth intervention group and a concurrent nonrandomized comparison group. A detailed description of the development of the GH program and the methods of the feasibility study has been previously published [33]. Key components related to this paper are described below.

\section{Study Participants}

The eligibility criteria for participation in the intervention group (GH) included being pregnant (30+ weeks gestation) or parent or main carer of an infant younger than 3 months, ownership of any type of mobile phone, ability to speak and read English, age 18 years or older, and residing in Australia. Participants were recruited using 3 methods: via their primary care providers in socioeconomically disadvantaged communities in 2 Australian states; face-to-face by researchers in first-time parent groups; or Web-based advertising. A concurrent nonrandomized 
comparison group (Baby's First Food, BFF) was recruited via online forums, social networking sites, and blogs and received usual care. The eligibility criteria for participation were the same as the intervention arm with the exception that participants were not required to own a mobile phone. Enrollment to both groups of the study involved the completion of a Web-based screening form, a consent form, and a baseline survey. Further details of the recruitment process and outcomes have been published elsewhere [34].

\section{The Growing Healthy Program}

In brief, the $\mathrm{GH}$ program aimed to encourage parents to engage in infant feeding practices that promote healthy rather than excess weight gain, with a focus on socioeconomically disadvantaged parents. The aims of the program were as follows:

- Promote breastfeeding.

- If breastfeeding was not possible, promote best practice formula feeding.

- Delay the introduction of solids to around 6 months of age but not before 4 months.

- Promote healthy first foods.

- Promote healthy infant feeding practices (including feeding to appetite, repeated neutral exposure to healthy food, and avoiding using food as a reward).

- Optimize infant dietary exposure to fruits and vegetables.

The main delivery media for the program were an app and website, which provided parents with evidence-based article and videos containing practical advice and strategies consistent with national guidelines on infant feeding from birth until 9 months of age. The development of the program was guided by the Behaviour Change Wheel and the Capability, Opportunity and Motivation model of behavior change [35]. For each program aim (target behavior), key determinants were identified using prior formative work $[36,37]$ and literature and mapped to intervention strategies. Participants received 3 personalized push notifications or text messages (short message service, SMS) per week targeting specific intervention strategies and behavior change techniques as detailed in our protocol paper [33]. Push notifications were also tailored to each infant's age and stage of development as well as their feeding mode (breast, formula, or mixed feeding), directing them to relevant content in the app. A weekly email was also sent that included the 3 messages for the week with links to the website. This was introduced part way through the intervention in response to the low number of push notifications being opened. Participants were also invited to join a Facebook group where one feeding message per week was posted by a moderator, and participants were encouraged to discuss practical experiences around infant feeding.

\section{Data Collection}

Data were collected at 3 time points via a Web-based survey: when infants were less than 3 months old (T1), when the infant was 6 months of age (T2), and when the infant was 9 months of age (T3). To compensate participants for the time involved in completing surveys, $\mathrm{GH}$ participants received a gift voucher worth Aus \$20 per survey completed, and BFF participants received Aus $\$ 40$ for the completion of 2 or more surveys.
Nonresponders to the survey were sent 3 email reminders, 1 week apart. We also collected data from analytics within the app.

\section{Assessment of Breastfeeding Duration and Exclusivity}

At T1, T2, and T3, parents were asked to report if their infant was currently breastfed and the infant's age in weeks when breastfeeding ceased if they were no longer breastfeeding. At T3, they were also asked about what they were feeding their infant: (1) breast milk, solids, and water or juices; (2) infant formula, solids, and water or juices; or (3) a combination of breast milk, infant formula, solids, and water or juices. Exclusive breastfeeding at $\mathrm{T} 2$ was determined by the question "Does baby have other fluids or food apart from breast milk?" All of those participants who were breastfeeding were asked additional questions at $\mathrm{T} 1$ and $\mathrm{T} 2$ about introduction of infant formula and the child's age at introduction of formula.

\section{Assessment of Best Practice Formula Feeding}

Formula preparation was assessed at each time point using a valid and reliable questionnaire [38] including the following items: follows instructions on the tin for loosely packed level scoops, adds water to the bottle first, and never adds more formula than the specifications on the tin. Additional questions about formula feeding practices were asked at each time point, including whether cereal was added to the bottle to ensure baby slept longer or stayed fuller longer, whether participants held their baby when feeding with a bottle, whether participants believed it was important for the baby to finish all the formula in the bottle, and whether participants allowed their baby's appetite to guide feeding. These questions were taken from the previously validated infant feeding questionnaire [39].

\section{Assessment of Timing of Solid Introduction}

At T1 and T2, parents were asked whether solids had been introduced and, if so, the infant's age in weeks at introduction.

\section{Assessment of Child Anthropometrics}

At each time point, the parent was asked to provide the most recent weight and length data from their infant's health record.

\section{Assessment of Demographic Characteristics}

The infant's sociodemographic characteristics including age, gender, birth order, and whether infants were Aboriginal or Torres Strait Islander were collected in the survey at T1. Also collected at $\mathrm{T} 1$ were parental characteristics, including primary carer's age, country of birth, relationship status, self-rated health, employment status, education level, and annual household income.

\section{Assessment of App Usage}

Participants' app usage was extracted from the GH activity log hosted on the Azure cloud in Southeast Australia. The key metrics collected included number of pages viewed per session ( 1 session=each day they accessed the app), number of sessions from the point participants activated the app until 9 months of the infant's age, and the number of push notifications opened. Furthermore, participants' device type (Android/iPhone) was also collected. 


\section{Assessment of App Acceptability}

At T3, participants were asked 25 questions relating to feasibility, acceptability, ease of use, and perceived usefulness of the app (and website) and the program overall. These survey questions were adapted from EMPOWER, an Australian mHealth intervention aimed at weight loss in adults [40], and the app quality assessment tool [29].

\section{Statistical Analysis}

Basic descriptive analysis and cross-tabulations were calculated. Baseline characteristic comparisons were made using chi-square test and $t$ test as appropriate to the variable type. Survival analysis was used to assess the difference in timing of feeding practices, including duration of any breastfeeding, timing of introduction of infant formula, and timing of solids introduction between the 2 groups-GH and BFF. Kaplan-Meier survival curves were used to assess the mean and median of breastfeeding duration and the timing of introduction of solids. Differences between the groups were assessed using Breslow test. Those cases where the child was reported as still being breastfed at T3 were classed as censored observations in the breastfeeding duration analysis. Cox proportional hazards regression models in the analysis of breastfeeding duration and time to solids introduction were used to account for covariates such as child's gender, whether first born, dummy use, maternal smoking status, mother's country of birth, parental education and work status, household income, and maternal age and prepregnancy BMI. Mother's self-rated health and possession of a health card were considered but due to high correlation with other covariates were excluded from the final analysis. Evaluation of the log-minus-log survival curves provided no evidence that the assumptions of proportional hazards were not met.

Multivariate logistic regression was used in the analysis of differences between GH and BFF for binary outcomes, including proportion exclusively breastfeeding; formula feeding outcomes; and proportion who had introduced solids before 4 months, after 6 months, and at 4, 4.5, 5, 5.5, and 6 months.

Differences between GH and BFF group continuous variables, which included child BMI z-score, weight, and length at time points between birth and T3, were assessed using mixed effect polynomial regression models with an unstructured covariance structure. A random intercept and a random slope for age to allow individual growth rates were fitted. Quadratic and cubic age variables to model nonlinear growth were included. Covariates included in the model were child's gender, whether first born, dummy use, maternal smoking status, mother's country of birth, parental education and work status, household income, and maternal age and prepregnancy BMI. All statistical analysis was performed using IBM Corporation SPSS version $24[41]$.

\section{Results}

\section{Study Participants}

A total of 909 subjects commenced enrollment into the study; however, 264 were ineligible predominately because they did not complete the baseline survey or their baby was older than 15 weeks or born prematurely (Figure 1). The final sample included 645 carer/child dyads at baseline (GH: 301; BFF: 344). Retention to the study was high at T2 (84.7\%) and T3 (80.3\%; Figure 1).

\section{Baseline Characteristics}

At enrollment, the mean age of the children in the GH group was significantly younger than the BFF group (7.0 weeks compared with 7.9 weeks). Furthermore, the GH group compared with the BFF group contained a significantly higher proportion of first-born children, with GH mothers being younger (30.4 years compared with 31.2 years), a lower proportion of $\mathrm{GH}$ mothers being Australian born $(84.1 \%$ vs $90.1 \%$ ), and a lower proportion in the highest household income category (29.4\% vs $36.8 \%)$. GH also contained a lower proportion of breastfeeding mothers and higher proportion of formula and mixed feeding mothers at baseline when compared with BFF $(P<.001)$. Other characteristics considered were not found to be significantly different at baseline between the 2 groups. Details of the baseline characteristics of study participants are provided in Table 1.

\section{App Usage}

Of the 301 participants, $260(86.4 \%)$ opted to access the program via the app, and $41(13.6 \%)$ via the website/SMS. App participants were provided with a code to enable them to download the app from either Google Play or the App Store, and $74.8 \%$ (225/301) of participants downloaded the app. More than half of the sample used iPhones (71.6\%), with $28.4 \%$ using Android phones and $11.9 \%$ website and SMS. Of app users, Android phone usage was higher among non-university-educated participants $(31.7 \%)$ compared with university-educated participants (24.5\%). App users were sent 3 push notifications each week, and on average, 11 push notifications were opened over the time of the study ( $8.0 \%$ of all notifications). App usage declined over time from $92.0 \%$ using the app at least once on enrollment to $38.2 \%$ at study completion when infants were aged 8 to 9 months of age (Figure 2), with a similar decline in the mean number of sessions using the app across the duration of the study (Figure 3). 
Figure 1. Flowchart detailing study participants.

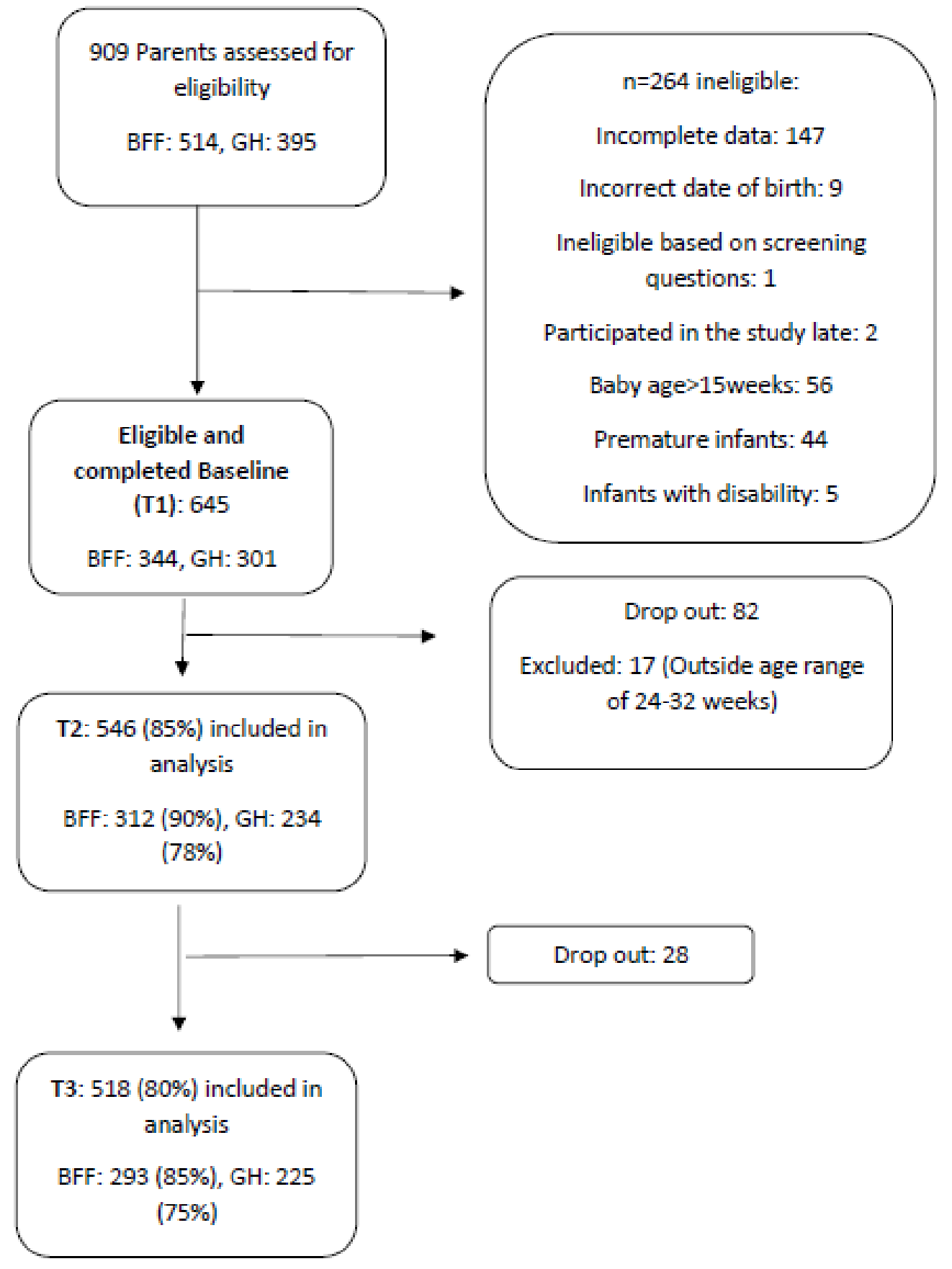


Table 1. Baseline characteristics of study participants by intervention group.

\begin{tabular}{|c|c|c|c|}
\hline Characteristics & Growing healthy $(\mathrm{n}=301)$ & Baby’s First Food (n=344) & $P$ value \\
\hline \multicolumn{4}{|l|}{ Child factors } \\
\hline Age (weeks) & $7.0(3.7)$ & $7.9(3.8)$ & .001 \\
\hline \multicolumn{4}{|l|}{ Gender, n (\%) } \\
\hline Boys & $150(49.8)$ & $167(48.5)$ & .74 \\
\hline Girls & $151(50.2)$ & $177(51.5)$ & \\
\hline \multicolumn{4}{|l|}{ Aboriginality, n (\%) } \\
\hline Nonaboriginal nor Torres Strait Islanders & $294(97.7)$ & $335(97.4)$ & .81 \\
\hline Aboriginal and/or Torres Strait Islanders & $7(2.3)$ & $9(2.6)$ & \\
\hline First-born baby, n (\%) & $173(57.5)$ & $133(38.7)$ & $<.001$ \\
\hline Dummy use at baseline, $\mathrm{n}(\%)$ & $164(54.5)$ & $163(47.4)$ & .07 \\
\hline \multicolumn{4}{|l|}{ Parental factors } \\
\hline Mother's age, years, mean (SD) & $30.4(4.7)$ & $31.2(4.4)$ & .04 \\
\hline Mother prepregnancy body mass index, $\mathrm{kg} / \mathrm{m}^{2,}$ mean (SD) & $26.6(5.7)$ & $27.2(6.8)$ & .23 \\
\hline Maternal current smoking status, $\mathrm{n}(\%)$ & $18(6.0)$ & $15(4.4)$ & .35 \\
\hline Maternal country of birth—Australian born, $\mathrm{n}(\%)$ & $253(84.1)$ & $310(90.1)$ & .02 \\
\hline Relationship status-married, n (\%) & $289(96.0)$ & $332(96.5)$ & .74 \\
\hline Health care card holder, n (\%) & $48(15.9)$ & $53(15.4)$ & .85 \\
\hline \multicolumn{4}{|l|}{ Maternal self-rated health, $\mathrm{n}(\%)$} \\
\hline Poor/fair & $30(10.0)$ & $28(8.1)$ & .51 \\
\hline Good & $116(38.5)$ & $152(44.2)$ & \\
\hline Very good & $124(41.2)$ & $131(38.1)$ & \\
\hline Excellent & $31(10.3)$ & $33(9.6)$ & \\
\hline Maternal education, $\mathbf{n}(\%)$ & $\mathrm{n}=\mathbf{2 8 9}$ & $\mathrm{n}=\mathbf{3 3 2}$ & \\
\hline Low & $61(21.1)$ & $56(16.4)$ & .29 \\
\hline Medium & $88(30.5)$ & $115(33.6)$ & \\
\hline High & $140(48.4)$ & $171(60.0)$ & \\
\hline Maternal working status, $n(\%)$ & $\mathrm{n}=301$ & $\mathrm{n}=342$ & \\
\hline Not working & $261(86.7)$ & $298(86.6)$ & .87 \\
\hline Working & $40(13.3)$ & $44(12.8)$ & \\
\hline Paternal education, $n(\%)$ & $\mathrm{n}=\mathbf{2 8 9}$ & $\mathrm{n}=\mathbf{3 3 2}$ & \\
\hline Low & $56(19.4)$ & $64(19.3)$ & .56 \\
\hline Medium & $144(49.8)$ & $153(46.1)$ & \\
\hline High & $89(30.8)$ & $115(34.6)$ & \\
\hline Paternal working status, n (\%) & $\mathrm{n}=\mathbf{2 8 9}$ & $\mathrm{n}=\mathbf{3 3 1}$ & \\
\hline Not working & $12(4.2)$ & $7(2.1)$ & .14 \\
\hline Working & $277(95.8)$ & $324(97.9)$ & \\
\hline Annual house income, Aus \$, n (\%) & $\mathrm{n}=\mathbf{3 0 1}$ & $\mathrm{n}=\mathbf{2 8 8}$ & \\
\hline$\leq 51,999$ & $35(13.7)$ & $44(15.3)$ & .02 \\
\hline $52,000-77,999$ & $79(31.0)$ & $57(19.8)$ & \\
\hline $78,000-99,999$ & $81(25.9)$ & $66(28.1)$ & \\
\hline 100,000 or more & $75(29.4)$ & $106(36.8)$ & \\
\hline
\end{tabular}




\begin{tabular}{clll}
\hline Characteristics & Growing healthy $(\mathrm{n}=301)$ & Baby's First Food $(\mathrm{n}=344)$ & $P$ value \\
\hline Breastfeeding & $196(65.1)$ & $245(71.2)$ & 4.001 \\
Formula feeding & $52(17.3)$ & $51(14.8)$ \\
Mixed feeding & $53(17.6)$ & \\
\hline
\end{tabular}

Figure 2. The percentage of participants who used the Growing healthy app throughout the 9-month program.

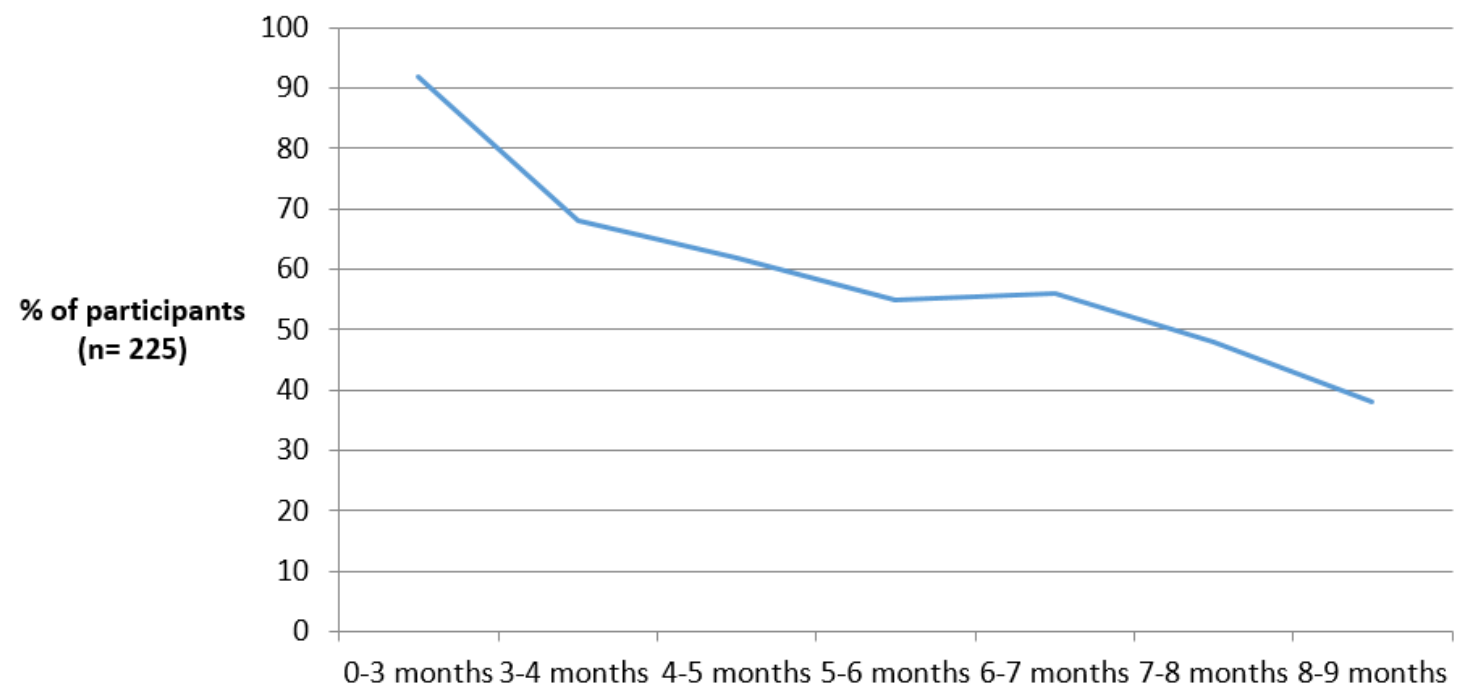

Age of baby

Figure 3. Participants' frequency of using the Growing healthy app throughout the 9-month program.

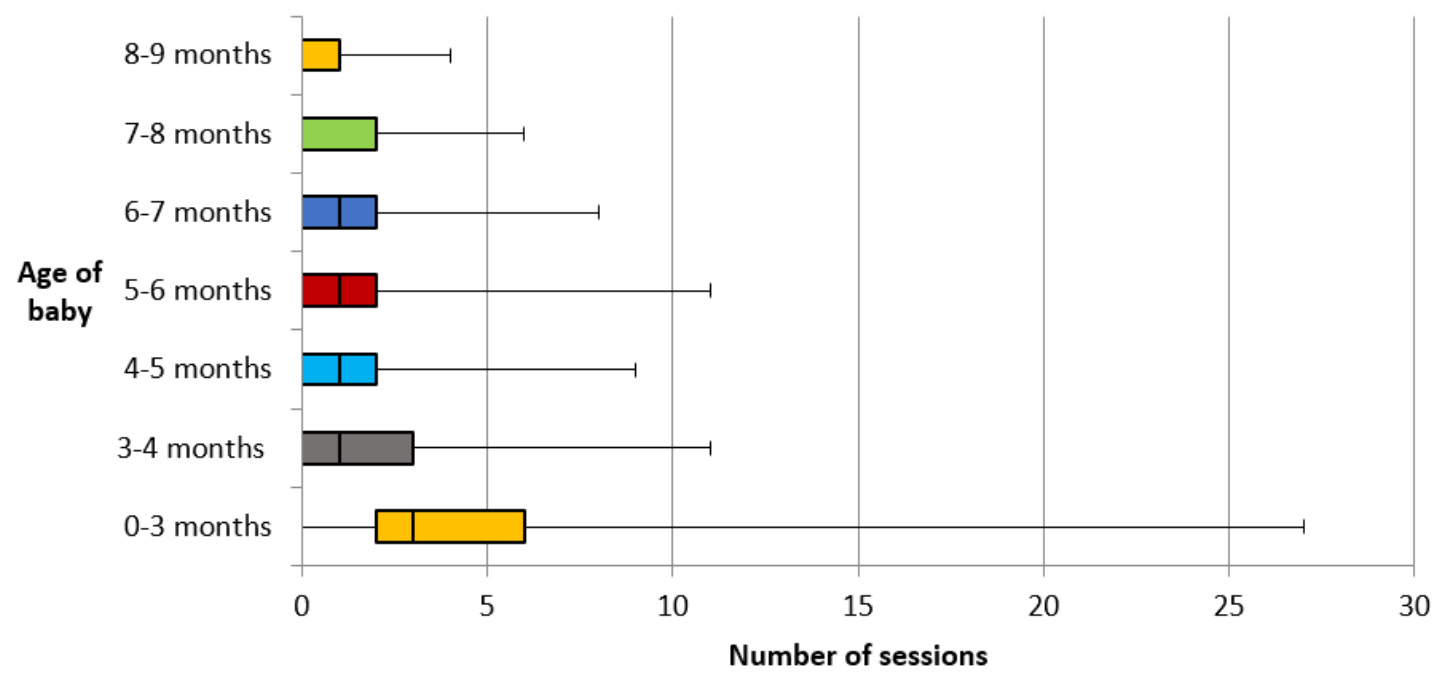

\section{Acceptability}

Overall, participants reported high levels of satisfaction with the program, with $88.1 \%$ agreeing that they liked the program and $84.6 \%$ informing that they would recommend it to a friend (Table 2). Most parents (86.1\%) reported that the app provided trustworthy information and was easy to understand (91.0\%) and use $(78.3 \%)$, with less than $5 \%$ of parents expressing concern about data usage when using the app. However, just over a quarter of parents reported that the app failed to work at times. Nearly $20 \%$ of participants who completed T3 reported disabling push notifications on their phone. For those receiving push notifications, a majority found them helpful, well suited to their baby's age and stage of development, and appropriate in terms of number and timing of messages. However, just over a third reported that the messages disappeared before they read them, and nearly $40 \%$ were unsure how to retrieve push notifications once they had disappeared from the screen. 
Table 2. Participant satisfaction with the Growing healthy program.

\begin{tabular}{|c|c|}
\hline Satisfaction item & Agree or strongly agree, $\mathrm{n}(\%)$ \\
\hline \multicolumn{2}{|l|}{ Overall program $(n=201)$} \\
\hline Overall I liked the Growing healthy program & $177(88.1)$ \\
\hline I would recommend the Growing healthy program to a friend & $170(84.6)$ \\
\hline Covered all I needed on feeding & $134(66.7)$ \\
\hline \multicolumn{2}{|l|}{ Growing healthy app $(n=166)$} \\
\hline Using the app was an enjoyable experience & $125(75.3)$ \\
\hline I can trust the information in the app & $143(86.1)$ \\
\hline The app did everything I expected it to do & $128(77.1)$ \\
\hline I liked the layout/look of the app & $131(78.9)$ \\
\hline The language used in the app was easy to understand & $151(91.0)$ \\
\hline I found the Growing healthy app easy to use & $130(78.3)$ \\
\hline I was concerned about data usage/costs when using the app & $7(4.2)$ \\
\hline Hard to navigate & $20(12.0)$ \\
\hline The Growing healthy app failed to work at times, $n=166$ & $43(25.9)$ \\
\hline \multicolumn{2}{|l|}{ Push notifications (n=126) } \\
\hline Push notifications often disappeared before I had a chance to open them & $43(34.1)$ \\
\hline I did not know how to retrieve push notifications once they disappeared from the screen & $50(39.7)$ \\
\hline I would prefer to receive text messages than push notifications & $37(29.4)$ \\
\hline \multicolumn{2}{|l|}{ Push notifications and text messages $(n=201)$} \\
\hline I was happy with the number of push notifications/texts received each week & $127(63.2)$ \\
\hline I was happy with the timing of push notifications/texts & $134(66.7)$ \\
\hline I found the push notifications/texts helpful & $127(63.2)$ \\
\hline I found the push notifications suited my baby's age and stage of development & $138(68.7)$ \\
\hline
\end{tabular}

\section{Feeding Outcomes}

\section{Breastfeeding}

The percentage of breastfeeding and mixed feeding mothers who reported having stopped breastfeeding by $\mathrm{T} 3$ was $31.6 \%$ and $28.5 \%$ for $\mathrm{GH}$ and BFF, respectively (Figure 4 ). The mean duration of any breastfeeding at T3 for GH was 39.6 weeks (95\% CI 37.5-41.8) compared with 39.0 weeks (95\% CI 37.3-40.7) for BFF. There was no statistically significant difference in the mean duration of any breastfeeding between the 2 groups $(P=.46)$. The hazard ratio for ceasing any breastfeeding in GH compared with BFF was not significantly different (hazard ratio 1.13; 95\% CI 0.74-1.74; $P=.57$ ). Stratified analysis by whether child first born (first-time vs non-first-time mothers) suggested that duration of any breastfeeding were not significantly different between $\mathrm{GH}$ and BFF, regardless of whether the child was first born or not. However, across both groups, the median duration of any breastfeeding for non-first-time mothers (41.9 weeks) were significantly longer than that of first-time mothers (37 weeks) $(P=.02)$. Cox hazard regression also revealed that first-time mothers were more likely to cease breastfeeding at $\mathrm{T} 3$ when compared with non-first-time mothers (hazard ratio 1.63; 95\% CI 1.06-2.52; $P=.03$ ). For maternal education, no differential effects on any breastfeeding duration were found.

The proportion of breastfeeding mothers who were exclusively breastfeeding at baseline was $84 \%(\mathrm{GH})$ and $83 \%(\mathrm{BFF})$. At 6 months, the proportion of exclusive breastfeeding among the $\mathrm{GH}$ and $\mathrm{BFF}$ groups was $9 \%$ and $13 \%$, respectively, which after adjustment for covariates showed no statistically significant difference between the groups (adjusted odds ratio, AOR 1.25; 95\% CI 0.46-3.32; $P=.65$ ). Among exclusive breastfeeding mothers, the mean duration of any breastfeeding was also similar between the 2 groups, with a mean duration of any breastfeeding for $\mathrm{GH}$ of 43.4 weeks (95\% CI 41.4-45.4) and for BFF of 41.0 weeks (95\% CI 39.7-42.4). 
Figure 4. Rates of any breastfeeding duration by intervention group (BFF: Baby's First Food; GH: Growing healthy).

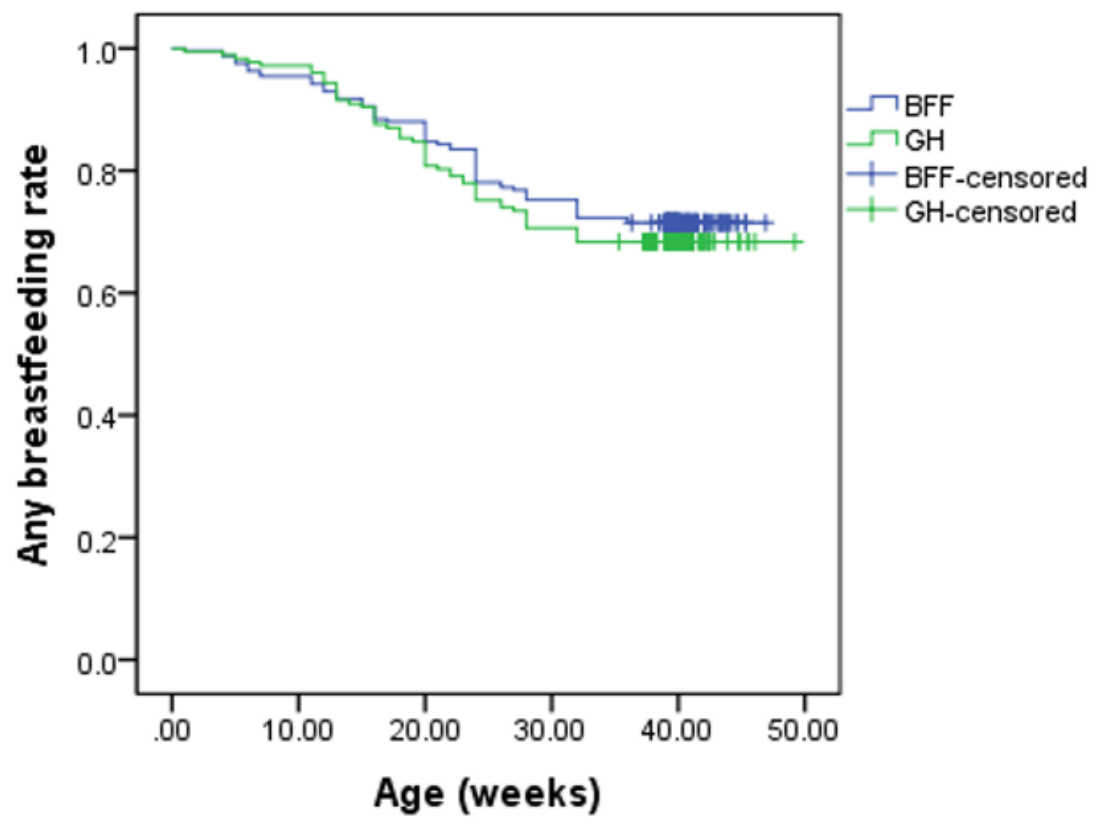

\section{Formula Feeding}

At all 3 time points, there was a trend for a higher proportion of GH participants preparing formula correctly compared with BFF group (Table 3). After adjusting for all covariates, formula preparation practice was not significantly different between groups (AOR 1.00; 95\% CI 0.48-2.10) at baseline. At T2 and T3, GH participants had slightly higher odds of preparing formula correctly in comparison with BFF (AOR of 1.25 at T2 and 1.67 at T3); however, neither was statistically significant. Most participants (99\%) from both GH and BFF did not add cereal to bottle during formula preparation (data not shown). At T3, parents in the GH group were less likely to hold their baby when giving a bottle compared with mothers in the BFF group (odds ratio 0.45 , 95\% CI $0.20-0.95$ ). At $\mathrm{T} 2$, but not baseline or $\mathrm{T} 3$, a higher proportion of mothers in $\mathrm{GH}$ than that of BFF believed that it is important to finish all formula in the bottle (AOR 2.65, 95\% CI 1.04-6.71). No significant difference was found for other formula feeding behaviors such as parents' attitude toward letting baby's appetite guide feeding (Table 3).

\section{Introduction of Solid Food}

The median age for solid introduction was 21.0 weeks for both GH and BFF (GH: 95\% CI 20.4-21.6; BFF: 95\% CI 20.3-21.6).
There was not a statistically significant difference in hazard rates for solid introduction timing between the 2 groups (hazard ratio $0.946 ; 95 \%$ CI $0.76-1.18)$. No statistically significant difference was found in the proportion introducing solids at different ages between GH and BFF groups (Table 3). Parents in the GH group were less likely to introduce solids before 4.5 months when compared with those in the BFF group (AOR 0.54-0.66); however, statistical significance was not reached $(P=.09)$. Few babies in either the $\mathrm{GH}$ or the BFF group received solid food before 4 months (Table 4).

\section{Infant Growth Trajectories}

Pairwise comparisons of predicted child BMI z-score, weight, and length at each time point from the mixed effect polynomial regression model between GH and BFF are shown in Table 5. BMI z-score of GH children from birth to $\mathrm{T} 3$ were similar to those in the BFF group $(P \geq .05)$. GH children compared with BFF children had lower weight from $\mathrm{T} 1$ to $\mathrm{T} 3$, but the mean difference was small $(0.12-0.32 \mathrm{~kg})$. Similarly, the height of $\mathrm{GH}$ children was also slightly shorter than BFF children from T1 to T3 (mean difference $0.47-1.11 \mathrm{~cm}$ ). Growth trajectories of BMI z-score, weight, and length were not significantly different between $\mathrm{GH}$ and $\mathrm{BFF}(P>.05$; Multimedia Appendix $1)$. 
Table 3. Comparison of infant feeding practices by intervention group.

\begin{tabular}{|c|c|c|c|c|c|}
\hline Variables & $\begin{array}{l}\text { Intervention (Growing } \\
\text { healthy) }\end{array}$ & $\begin{array}{l}\text { Control (Baby's First } \\
\text { Food) }\end{array}$ & Total & $\begin{array}{l}\text { Adjusted odds ratio }{ }^{a} \\
(95 \% \text { CI })\end{array}$ & $P$ value \\
\hline \multicolumn{6}{|c|}{ Exclusive breastfeeding } \\
\hline $\mathbf{T} 1, \mathbf{n}$ & 195 & 246 & 441 & & \\
\hline Yes, n $(\%)$ & $164(84.1)$ & $202(82.1)$ & $366(82.9)$ & $1.37(0.72-2.66)$ & .34 \\
\hline $\mathbf{T} 2, \mathbf{n}$ & 111 & 160 & 271 & & \\
\hline Yes, n (\%) & $10(9.0)$ & $20(12.5)$ & $31(11.4)$ & $1.22(0.46-3.32)$ & 69 \\
\hline \multicolumn{6}{|c|}{ Prepared formula correctly } \\
\hline $\mathbf{T} 1, \mathbf{n}$ & 105 & 99 & 204 & & \\
\hline Yes, n (\%) & $48(45.7)$ & $38(38.4)$ & $86(42.2)$ & $1.00(0.48-2.10)$ & $>.99$ \\
\hline $\mathbf{T} 2, \mathbf{n}$ & 101 & 116 & 217 & & \\
\hline Yes, n (\%) & $58(57.4)$ & $56(48.3)$ & $114(52.5)$ & $1.25(0.64-2.44)$ & .52 \\
\hline T3, n & 108 & 137 & 245 & & \\
\hline Yes, n (\%) & $66(61.1)$ & $71(51.8)$ & $137(55.9)$ & $1.67(0.87-3.20)$ & .13 \\
\hline \multicolumn{6}{|c|}{ Held baby when giving a bottle } \\
\hline $\mathbf{T} 1, \mathbf{n}$ & 105 & 99 & 204 & & \\
\hline Yes, n (\%) & $103(98.1)$ & $96(97.0)$ & $199(97.5)$ & $1.71(0.28-10.64)$ & .57 \\
\hline $\mathrm{T} 2(\mathrm{~N}=217) \mathrm{n}$ & 101 & 116 & & & \\
\hline Yes, n $(\%)$ & $87(86.1)$ & $103(88.8)$ & $190(87.6)$ & $0.73(0.27-1.97)$ & .54 \\
\hline $\mathbf{T 3}, \mathbf{n}$ & 115 & 137 & 252 & & \\
\hline Yes, $\mathrm{n}(\%)$ & $73(63.5)$ & $102(74.5)$ & $175(69.4)$ & $0.48(0.23-1.00)$ & .05 \\
\hline \multicolumn{6}{|c|}{ Important to finish all formula in the bottle } \\
\hline $\mathbf{T} 1, \mathbf{n}$ & 105 & 99 & 204 & & \\
\hline Yes, n $(\%)$ & $20(19.1)$ & $24(24.2)$ & $44(21.6)$ & $0.72(0.3-1.69)$ & .45 \\
\hline $\mathbf{T} 2, \mathbf{n}$ & $\mathrm{n}=101$ & $\mathrm{n}=116$ & 217 & & \\
\hline Yes, $\mathrm{n}(\%)$ & $26(25.7)$ & $15(12.9)$ & $41(18.9)$ & $2.65(1.04-6.71)$ & .04 \\
\hline $\mathbf{T 3}, \mathbf{n}$ & $\mathrm{n}=115$ & $\mathrm{n}=121$ & 252 & & \\
\hline Yes, $\mathrm{n}(\%)$ & $21(18.1)$ & $16(13.2)$ & $37(14.7)$ & $1.60(0.66-3.88)$ & .30 \\
\hline \multicolumn{6}{|c|}{ Let baby's appetite guide feeding } \\
\hline $\mathbf{T 1}, \mathbf{n}$ & 53 & 51 & 104 & & \\
\hline Yes, n (\%) & $46(86.8)$ & $44(86.3)$ & $90(86.5)$ & $0.87(0.12-6.48)$ & .89 \\
\hline $\mathbf{T} 2, \mathbf{n}$ & $\mathrm{n}=30$ & $\mathrm{n}=33$ & 63 & & \\
\hline Yes, n (\%) & $22(73.3)$ & $23(69.7)$ & $45(71.4)$ & $2.32(0.29-18.24)$ & .43 \\
\hline
\end{tabular}

${ }^{a}$ Logistic regression adjusted for child age, gender, whether first born, dummy use, maternal age, smoking status, country of birth, maternal and paternal education, maternal and paternal working status, maternal prepregnancy body mass index, and house income. 
Table 4. Comparison of age at which solid foods were introduced by intervention group.

\begin{tabular}{|c|c|c|c|c|c|}
\hline Variables & Total, $(n=481)$ & $\begin{array}{l}\text { Intervention (Growing } \\
\text { healthy), } \mathrm{n}=208\end{array}$ & $\begin{array}{l}\text { Control (Baby's } \\
\text { First Food), n=273 }\end{array}$ & $\begin{array}{l}\text { Adjusted odds ratio }{ }^{\mathrm{a}} \\
(95 \% \mathrm{CI})\end{array}$ & $P$ value \\
\hline \multicolumn{6}{|l|}{ Age at which solids were introduced } \\
\hline Before 4 months (0-15 weeks), n (\%) & $21(4.4)$ & $10(4.8)$ & $11(4.0)$ & $0.46(0.12-1.77)$ & .26 \\
\hline At 4 months (0-16 weeks), n (\%) & $64(13.3)$ & $28(13.5)$ & $36(13.2)$ & $0.54(0.26-1.09)$ & .09 \\
\hline At 4.5 months $(0-18$ weeks $), \mathrm{n}(\%)$ & $134(27.9)$ & $56(26.9)$ & $78(28.6)$ & $0.63(0.38-1.06)$ & .08 \\
\hline At 5 months (0-20 weeks) & $234(48.6)$ & $104(50.0)$ & $130(47.6 \%)$ & $0.92(0.58-1.44)$ & .70 \\
\hline At 5.5 months $(0-22$ weeks), n (\%) & $304(63.2)$ & $145(69.7)$ & $159(58.2)$ & $1.42(0.89-2.26)$ & .14 \\
\hline At 6 months (0-24 weeks), n (\%) & $409(85.0)$ & $184(88.5)$ & $225(82.4)$ & $1.14(0.61-2.11)$ & .68 \\
\hline After 6 months (0-25 weeks), n (\%) & $433(90.0)$ & $194(93.3)$ & $239(87.5)$ & $1.22(0.57-2.62)$ & .61 \\
\hline
\end{tabular}

${ }^{a}$ Logistic regression adjusted for child age, gender, whether first born, dummy use, maternal age, smoking status, country of birth, maternal and paternal education, maternal and paternal working status, maternal prepregnancy body mass index, and house income.

Table 5. Predicted mean child body mass index (BMI) z-score, weight, and length of Growing healthy (GH) and Baby's First Food (BFF) at birth, 3 months (T1), 6 months (T2), and 9 months (T3).

\begin{tabular}{clll}
\hline Anthropometry & Growing healthy, predicted mean ${ }^{\mathrm{a}}(95 \% \mathrm{CI})$ & ${\text { Baby's First Food, predicted mean }{ }^{\mathrm{a}}(95 \% \mathrm{CI})} P$ value \\
\hline BMI $^{\mathbf{b}}$ z-score & & & \\
Birth & $0.22(0.22-0.34)$ & $0.33(0.22-0.44)$ & .21 \\
T1 & $1.57(1.45-1.69)$ & $1.71(1.59-1.83)$ & .11 \\
T2 & $0.44(0.31-0.57$ & $0.26(0.14-0.38)$ & .05 \\
T3 & $0.24(0.09-0.38$ & $0.28(0.16-0.41)$ & .61 \\
Weight & $3.49(3.43-3.56)$ & $3.55(3.48-3.61)$ & .26 \\
Birth & $4.62(4.55-4.69)$ & $4.76(4.70-4.82)$ & .003 \\
T1 & $7.23(7.15-7.30)$ & $7.55(7.48-7.61)$ & $<.001$ \\
T2 & $8.62(8.54-8.70)$ & $8.78(8.71-8.85)$ & .003 \\
T3 & & & .39 \\
Length & $50.55(50.28-50.82)$ & $50.71(50.46-50.97)$ & .01 \\
Birth & $54.97(54.70-55.25)$ & $55.51(55.25-55.77)$ & $<.001$ \\
T1 & $64.97(64.67-65.27)$ & $66.08(65.81-66.36)$ & .03 \\
T2 & $69.78(69.46-70.10)$ & $70.25(69.97-70.53)$ & \\
T3 & & \\
\hline
\end{tabular}

${ }^{\text {a }}$ Predicted means derived from mixed effect polynomial regression model with adjustment for child age, gender, whether first born, dummy use, maternal age, smoking status, country of birth, maternal and paternal education, maternal and paternal working status, maternal prepregnancy body mass index, and household income.

${ }^{b}$ BMI: body mass index.

\section{Discussion}

\section{Principal Findings}

This is the first study, to our knowledge, to report on the feasibility and effectiveness of an mHealth intervention for prevention of obesity in infancy. Our findings support the use of mHealth as a feasible and acceptable mode of delivery of an intervention targeting parents' infant feeding behaviors due to participants' high levels of reported satisfaction and retention to the program, despite some technical difficulties using the app and decline in engagement over time. We were, however, unable to demonstrate any impact of the intervention on the target behaviors and outcomes of breastfeeding duration or exclusivity, timing of introduction of solids, or infant growth trajectories. The findings suggest that the GH intervention may have positively impacted on formula preparation practices, although this was not significant in fully adjusted models and requires confirmation in an adequately powered randomized controlled trial.

The findings of this study support mHealth as an acceptable mode of delivery for obesity prevention interventions in infancy, particularly those targeting infant feeding, with high rates of 
recruitment [42] and a retention rate of $80 \%$ at 9 months follow-up. It is important to acknowledge that the high retention rates might reflect, in part, the payment offered for survey completion and the use of 3 reminders. Acceptability of the program is supported by the high rates of reported user satisfaction with the program. This is consistent with findings from our qualitative follow-up interviews with parents [43] where they reported engagement with the program was promoted by the credibility of the program source, the user-friendly interface, and tailoring of content and push notifications to the baby's age and key transition points. Our findings are congruent with existing research, which suggests that parents are increasingly relying on online source of information for infant feeding and care [23-27].

However, a number of factors may have reduced engagement with the program. Over a quarter of participants reported that the app failed to work at times. Technical problems did arise in the study, including operating system updates for both iOS and Android systems disabling the app for a short period of time. Parents who changed mobile phones during the study were required to contact the research team to obtain another code to access the app, which may have further reduced app usage. Furthermore, although push notifications were perceived to be relevant and timely, nearly $40 \%$ of participants were unsure how to retrieve push notifications once they had disappeared from the screen. This might explain the relatively low proportion $(8 \%)$ of push notifications opened. Given that push notifications were the primary mechanism to drive parents to engage with the app content, this was very likely to have limited the dose of the intervention received and its subsequent impact on infant feeding behaviors and outcomes. This is further supported by app analytics data, which indicate that the use of the app did indeed decline over the duration of the study.

Understanding factors influencing engagement with mHealth programs and how these can be maximized over time is critical to program effectiveness. Our quantitative analysis of app usage [44] revealed higher engagement with the program among those recruited by their health practitioner, those who registered when their infant was younger, those who were first-time mothers, and those using both the app and website (via email links) compared with those using the app alone. This suggests that, to maximize engagement and potential impact, consideration should be given in the future to focus on recruiting first-time parents, with the help of health practitioners during the early postnatal or antenatal period. Future iterations of the program should include design features to improve access to push notifications and to maximize engagement over time using multiple methods (eg, email and push notifications) as well as the inclusion of more interactive features such as a forum and other tools to promote ongoing engagement. Technical issues also need to be addressed in a timely manner, including accommodating any operating system updates to ensure the program is functional at all times.

In addition to intervention dose, the lack of intervention effect may also be because of the sample size of this feasibility study, which was not powered to detect differences between groups but rather inform sample size calculations for a subsequent larger randomized controlled trial. The study was limited by the significant difference in a number of baseline characteristics between the study groups. Although baseline differences were controlled for in the statistical analysis, this reduces the power to detect differences in key outcomes between the groups.

The timing of the intervention may have contributed to the program's limited impact on outcomes, particularly for breastfeeding. The average age of infants at the time of enrollment was 7 to 8 weeks, suggesting that the intervention missed the critical period for breastfeeding support, with national data indicating that $40 \%$ of mothers introduce formula by 1 month of age [14]. Research has also indicated that plans about whether a mother will breastfeed and for how long are made antenatally [45], and this was consistent with our qualitative findings [43] where mothers reported that plans for feeding their infant were made before enrolling in the program. This highlights the importance of commencing the program before birth and providing very early postnatal breastfeeding support to influence breastfeeding outcomes.

The GH program specifically targeted socioeconomically disadvantaged parents due to the socioeconomic disparities in obesity risk emerging in early infancy [17]. Our findings suggest that we had some limited success in reaching these parents, with just over half of mothers $(51.6 \%)$ and nearly $70 \%$ of fathers not having a university-level education, with education commonly used as a proxy for socioeconomic position [46]. This is similar to the national average [47] but higher than that reported in other group-based obesity prevention trials in infancy. For example, the proportion of mothers without a university education was $46 \%$ in the InFANT trial [48] and $42 \%$ in the NOURISH trial [49]. However, a home-visiting trial in disadvantaged communities managed to recruit three-quarters of participants without a university education [50]. Surprisingly, we found no difference in the education levels of mothers when recruited by primary health care practitioners in disadvantaged communities and those recruited via social media [42]. It may be that primary health care practitioners were more selective in offering the program to less vulnerable parents. Our findings indicate the importance of catering for Android phone users if mHealth programs target socioeconomically disadvantaged parents, with higher Android phone usage among those without a university education compared with university-educated mothers in our sample. Given the greater need in socioeconomically disadvantaged parents, further research is required to ascertain how best to engage these parents in obesity prevention interventions and indeed whether mHealth programs provide a useful mode of delivery.

The use of mHealth for obesity prevention in early childhood is a rapidly growing field, with a number of trials underway [51-54]. However, we are unaware of any other studies reporting the outcomes of a mobile phone app targeting parents' healthy infant feeding practices. A recent meta-analysis of 16 studies in developed countries has shown e-technologies (including SMS, Web, and interactive computer agent) to be effective in improving rates of breastfeeding initiation, duration, and exclusivity [55]. This review however did not include any studies utilizing a mobile phone app. Only one other published study [56] has reported the effectiveness of an mHealth program targeting infant feeding. That study [56], by Jiang et al in 
Shanghai, China, found that a weekly SMS from third trimester of pregnancy to 12 months postpartum resulted in a significantly higher rate of exclusive breastfeeding at 6 months and a significantly lower rate of the introduction of solid foods before 4 months. However, the intervention had no effect on other infant feeding practices, including taking a bottle to bed, drinking from a cup, or using food as a reward.

\section{Strengths and Limitations}

The key strength of this study was that the intervention was informed by behavior change theory and extensive formative work and had high rates of retention. The use of a quasi-experimental study design was a limitation with a number of baseline differences between the intervention and the comparison groups; however, these differences were controlled for in the statistical analysis. There was also a likely selection bias in that the mothers who took part in both groups may have been more interested and motivated to achieve desirable infant feeding practices by virtue of their interest in this research despite having similar levels of education as national average [47]. This is supported by the high rates of exclusive breastfeeding at baseline ( $84 \%$ in BFF and $82 \%$ in GH compared with national average of $48 \%$ in infants less than 3 months of age [14]) and low proportion introducing solids early (13\% at 4 months in both groups compared with national average of $35 \%$ [14]). This may have limited the ability to detect intervention effect. A randomized recruitment strategy with a more representative sample of mothers might offer more potential to show improvements in infant feeding practices. Measurement of infant feeding behaviors based on self-report in both groups was no doubt subject to social desirability bias. Parental report of weight and length may be subject to transcription errors and would be more accurately collected by investigators.

\section{Conclusions}

Our study design was feasible in that there was an excellent retention rate over time for participants who completed the enrollment survey, and the results provide a useful estimate on which to base a sample size calculation for a larger study. An mHealth intervention using a smartphone app to promote healthy infant feeding behaviors is a feasible and acceptable mode for delivering obesity prevention intervention to parents but further work is required to sustained engagement and use over time. The limited impact of the program on key measureable infant feeding outcomes may reflect that some participants received a low intervention dose because of unforeseen technical problems, the timing of the program, participant selection bias, and/or limitations in the study design. It is recommended that mHealth programs targeting infant feeding commence antenatally and future iterations of the program have contingencies in place to address technical issues in a timely manner and design features to maximize engagement over time. Future research using larger randomized controlled trial designs are required to determine the effectiveness of mHealth programs for obesity prevention in infancy.

\section{Acknowledgments}

The research reported in this paper is a project of the Australian Primary Health Care Research Institute, which was supported by a grant from the Australian Government Department of Health and Ageing. The information and opinions contained in it do not necessarily reflect the views or policy of the Australian Primary Health Care Research Institute or the Australian Government Department of Health and Ageing. The authors thank the parents who participated in the trial and the participating practitioners for their time in recruiting participants and their valuable insights throughout the trial. We thank Leva Azadi for her early work on the breastfeeding components, Kate Dullaghan for her editorial work on the app content, and Professor Cathrine Fowler for her support and review of app content. We are also grateful to Louisa Wilson, our research assistant. RL is supported by a National Health \& Medical Research Council Early Career Research Fellowship, ID 1089415.

\section{Authors' Contributions}

RL, EDW, ST, CGR, RE, and KC all contributed to the conceptualization of the study and development of the app content. KL developed the programming behind the app and website and measurement of program analytics. EL managed the data collection, whereas MZ undertook the data analysis, with input from SL. RL and EDW wrote the first draft of the paper. All authors reviewed and contributed to drafts of the paper and approved the final manuscript.

\section{Conflicts of Interest}

None declared.

\section{Multimedia Appendix 1}

Mixed effects polynomial regression model for BMI z-score, weight, and length trajectories.

[PDF File (Adobe PDF File), 29KB-Multimedia Appendix 1]

\section{References}

1. World Health Organization. Geneva: World Health Organization; 2016. Report of the Commission on Ending Childhood Obesity URL: http://apps.who.int/iris/bitstream/10665/204176/1/9789241510066 eng.pdf? [accessed 2018-03-07] [WebCite Cache ID 6xk3pgDJu] 
2. Webcitation. 2013. Australian Bureau of Statistics URL: http://www.webcitation.org/6tbbdz0Z1[WebCite Cache ID 6tbbdz0Z1]

3. Pelone F, Specchia ML, Veneziano MA, Capizzi S, Bucci S, Mancuso A, et al. Economic impact of childhood obesity on health systems: a systematic review. Obes Rev 2012 May;13(5):431-440. [doi: 10.1111/j.1467-789X.2011.00968.x] [Medline: 22212590]

4. Baird J, Fisher D, Lucas P, Kleijnen J, Roberts H, Law C. Being big or growing fast: systematic review of size and growth in infancy and later obesity. BMJ 2005 Oct 22;331(7522):929 [FREE Full text] [doi: 10.1136/bmj.38586.411273.E0] [Medline: $\underline{16227306}$ ]

5. Druet C, Stettler N, Sharp S, Simmons RK, Cooper C, Smith GD, et al. Prediction of childhood obesity by infancy weight gain: an individual-level meta-analysis. Paediatr Perinat Epidemiol 2012 Jan;26(1):19-26. [doi: 10.1111/j.1365-3016.2011.01213.x] [Medline: 22150704]

6. Koletzko B, von Kries R, Closa R, Escribano J, Scaglioni S, Giovannini M, European Childhood Obesity Trial Study Group. Lower protein in infant formula is associated with lower weight up to age $2 \mathrm{y}$ : a randomized clinical trial. Am $\mathrm{J}$ Clin Nutr 2009 Jun;89(6):1836-1845. [doi: 10.3945/ajcn.2008.27091] [Medline: 19386747]

7. Lucas A, Lockton S, Davies PS. Randomised trial of a ready-to-feed compared with powdered formula. Arch Dis Child 1992 Jul;67(7):935-939 [FREE Full text] [Medline: 1519960]

8. Wood CT, Skinner AC, Yin HS, Rothman RL, Sanders LM, Delamater AM, et al. Bottle size and weight gain in formula-fed infants. Pediatrics 2016 Jul;138(1) [FREE Full text] [doi: 10.1542/peds.2015-4538] [Medline: 27273748]

9. Grote V, Schiess SA, Closa-Monasterolo R, Escribano J, Giovannini M, Scaglioni S, European Childhood Obesity Trial Study Group. The introduction of solid food and growth in the first $2 \mathrm{y}$ of life in formula-fed children: analysis of data from a European cohort study. Am J Clin Nutr 2011 Dec;94(6 Suppl):1785S-1793S. [doi: 10.3945/ajcn.110.000810] [Medline: 21918213]

10. Mihrshahi S, Battistutta D, Magarey A, Daniels LA. Determinants of rapid weight gain during infancy: baseline results from the NOURISH randomised controlled trial. BMC Pediatr 2011 Nov 7;11:99 [FREE Full text] [doi: 10.1186/1471-2431-11-99] [Medline: 22054415]

11. Gibbs BG, Forste R. Socioeconomic status, infant feeding practices and early childhood obesity. Pediatr Obes 2014 Apr;9(2):135-146. [doi: 10.1111/j.2047-6310.2013.00155.x] [Medline: 23554385]

12. World Health Organization. 2003. Global Strategy for Infant and Young Child Feeding URL: http://apps.who.int/iris/ bitstream/10665/42590/1/9241562218.pdf [accessed 2018-03-07] [WebCite Cache ID 6xjrQN3Jh]

13. Child Australia Online Learning Center. Canberra: NHMRC; 2003. Dietary guidelines for children and adolescents in Australia incorporating the infant feeding guidelines for health URL: http://childaustralia.mrooms.net/pluginfile.php/4134/ mod page/content/38/diet-guidelines.pdf [accessed 2018-03-07] [WebCite Cache ID 6xjrX33kE]

14. Webcitation. 2011. 2010 Australian National Infant Feeding Survey URL: http://www.webcitation.org/6tbbD06vw[WebCite Cache ID 6tbbD06vw]

15. Centers for Disease Control and Prevention. Breastfeeding Report Card URL: https://www.cdc.gov/breastfeeding/data/ reportcard.htm [accessed 2017-09-20] [WebCite Cache ID 6tbfiuwOR]

16. Wake M, Hardy P, Canterford L, Sawyer M, Carlin JB. Overweight, obesity and girth of Australian preschoolers: prevalence and socio-economic correlates. Int J Obes (Lond) 2007 Jul;31(7):1044-1051. [doi: 10.1038/sj.ijo.0803503] [Medline: $\underline{17146451]}$

17. Wijlaars LPMM, Johnson L, van Jaarsveld CHM, Wardle J. Socioeconomic status and weight gain in early infancy. Int J Obes (Lond) 2011 Jul;35(7):963-970 [FREE Full text] [doi: 10.1038/ijo.2011.88] [Medline: 21540830]

18. Cameron A, Spence A, Laws R, Hesketh K, Lioret S, Campbell KJ. A review of the relationship between socioeconomic position and the early-life predictors of obesity. Curr Obes Rep 2015 Sep;4(3):350-362. [doi: 10.1007/s13679-015-0168-5] [Medline: 26627493]

19. Hillier-Brown FC, Bambra CL, Cairns JM, Kasim A, Moore HJ, Summerbell CD. A systematic review of the effectiveness of individual, community and societal level interventions at reducing socioeconomic inequalities in obesity amongst children. BMC Public Health 2014 Aug 11;14:834 [FREE Full text] [doi: 10.1186/1471-2458-14-834] [Medline: 25113624]

20. Pewglobal. Smartphone Ownership and Internet Usage Continues to Climb in Emerging Economies URL: http://www. pewglobal.org/2016/02/22/smartphone-ownership-and-internet-usage-continues-to-climb-in-emerging-economies/[WebCite Cache ID 6tbfaxVmH]

21. Nielsen. 2016. Looking at the Media DNA of Working and Stay-At-Home Mothers: Nielsen Total Audience Report: Q3 2016 URL: http://www.nielsen.com/us/en/insights/news/2016/ mom-genes-looking-at-the-media-dna-of-working-and-stay-at-home-moms.html [accessed 2018-03-07] [WebCite Cache ID 6tbg0gKw8]

22. Thorslund K, Hanse JJ, Axberg U. Universal parental support-How to reach out: a cross-sectional random sample of Swedish parents. BMC Public Health 2014;14:1064. [doi: 10.1186/1471-2458-14-1064]

23. Baker S, Sanders MR, Morawska A. Who uses online parenting support? a cross-sectional survey exploring australian parents' internet use for parenting. J Child Fam Stud 2017;26(3):916-927. [doi: 10.1007/s10826-016-0608-1] 
24. Bernhardt J, Felter EM. Online pediatric information seeking among mothers of young children: results from a qualitative study using focus groups. J Med Internet Res 2004 Mar 1;6(1):e7 [FREE Full text] [doi: 10.2196/jmir.6.1.e7] [Medline: $\underline{15111273]}$

25. Guendelman S, Broderick A, Mlo H, Gemmill A, Lindeman D. Listening to communities: mixed-method study of the engagement of disadvantaged mothers and pregnant women with digital health technologies. J Med Internet Res 2017 Jul 5;19(7):e240 [FREE Full text] [doi: 10.2196/jmir.7736] [Medline: 28679489]

26. Lupton D. The use and value of digital media for information about pregnancy and early motherhood: a focus group study. BMC Pregnancy Childbirth 2016 Dec 19;16(1):171 [FREE Full text] [doi: 10.1186/s12884-016-0971-3] [Medline: 27435182]

27. Slomian J, Bruyère O, Reginster JY, Emonts P. The internet as a source of information used by women after childbirth to meet their need for information: a web-based survey. Midwifery 2017 May;48:46-52. [doi: 10.1016/j.midw.2017.03.005] [Medline: 28324809]

28. Guerra-Reyes L, Christie VM, Prabhakar A, Harris AL, Siek KA. Postpartum health information seeking using mobile phones: experiences of low-income mothers. Matern Child Health J 2016;20(Suppl 1):13-21 [FREE Full text] [doi: 10.1007/s10995-016-2185-8] [Medline: 27639571]

29. Taki S, Campbell K, Russell C, Elliott R, Laws R, Denney-Wilson E. Infant feeding websites and apps: a systematic assessment of quality and content. Interact J Med Res 2015 Sep 29;4(3):e18 [FREE Full text] [doi: 10.2196/ijmr.4323] [Medline: 26420339]

30. Free C, Phillips G, Galli L, Watson L, Felix L, Edwards P, et al. The effectiveness of mobile-health technology-based health behaviour change or disease management interventions for health care consumers: a systematic review. PLoS Med 2013;10(1):e1001362 [FREE Full text] [doi: 10.1371/journal.pmed.1001362] [Medline: 23349621]

31. Militello LK, Kelly SA, Melnyk BM. Systematic review of text-messaging interventions to promote healthy behaviors in pediatric and adolescent populations: implications for clinical practice and research. Worldviews Evid Based Nurs 2012 Apr;9(2):66-77. [doi: 10.1111/j.1741-6787.2011.00239.x] [Medline: 22268959]

32. Schoeppe S, Alley S, Van Lippevelde W, Bray NA, Williams SL, Duncan MJ, et al. Efficacy of interventions that use apps to improve diet, physical activity and sedentary behaviour: a systematic review. Int J Behav Nutr Phys Act 2016 Dec 07;13(1):127 [FREE Full text] [doi: 10.1186/s12966-016-0454-y] [Medline: 27927218]

33. Denney-Wilson E, Laws R, Russell CG, Ong KL, Taki S, Elliot R, et al. Preventing obesity in infants: the growing healthy feasibility trial protocol. BMJ Open 2015 Nov 30;5(11):e009258 [FREE Full text] [doi: 10.1136/bmjopen-2015-009258] [Medline: 26621519]

34. Laws RA, Litterbach EK, Denney-Wilson EA, Russell CG, Taki S, Ong KL, et al. A comparison of recruitment methods for an mHealth intervention targeting mothers: lessons from the growing healthy program. J Med Internet Res 2016 Sep 15;18(9):e248 [FREE Full text] [doi: 10.2196/jmir.5691] [Medline: 27634633]

35. Michie S, van Stralen MM, West R. The behaviour change wheel: a new method for characterising and designing behaviour change interventions. Implement Sci 2011 Apr 23;6:42 [FREE Full text] [doi: 10.1186/1748-5908-6-42] [Medline: 21513547]

36. Russell CG, Taki S, Azadi L, Campbell KJ, Laws R, Elliott R, et al. A qualitative study of the infant feeding beliefs and behaviours of mothers with low educational attainment. BMC Pediatr 2016 Dec 21;16:69 [FREE Full text] [doi: 10.1186/s12887-016-0601-2] [Medline: 27209010]

37. Laws R, Campbell KJ, van der Pligt P, Ball K, Lynch J, Russell G, et al. Obesity prevention in early life: an opportunity to better support the role of maternal and child health nurses in Australia. BMC Nurs 2015;14:26 [FREE Full text] [doi: 10.1186/s12912-015-0077-7] [Medline: 25972765]

38. Lakshman RR, Landsbaugh JR, Schiff A, Hardeman W, Ong KK, Griffin SJ. Development of a questionnaire to assess maternal attitudes towards infant growth and milk feeding practices. Int J Behav Nutr Phys Act 2011;8:35 [RREE Full text] [doi: 10.1186/1479-5868-8-35]

39. Baughcum AE, Powers SW, Johnson SB, Chamberlin LA, Deeks CM, Jain A, et al. Maternal feeding practices and beliefs and their relationships to overweight in early childhood. J Dev Behav Pediatr 2001 Dec;22(6):391-408. [Medline: 11773804]

40. Ball K, Ong KL, Jackson M, Zhang J, McNaughton S, Crawford D. EMPOWER: the development and pilot-testing of an evidence-based weight loss mobile telephone app. Obes Res Clin Pract 2014;8:5. [doi: 10.1016/j.orcp.2014.10.009]

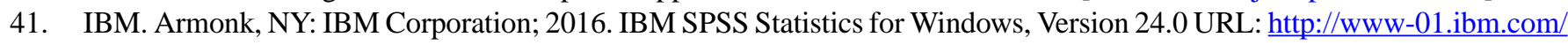
support/docview.wss?uid=swg27047057

42. Laws RA, Litterbach EK, Denney-Wilson EA, Russell CG, Taki S, Ong KL, et al. A comparison of recruitment methods for an mHealth intervention targeting mothers: lessons from the growing healthy program. J Med Internet Res 2016 Sep 15;18(9):e248 [FREE Full text] [doi: 10.2196/jmir.5691] [Medline: 27634633]

43. Litterbach EK, Russell CG, Taki S, Denney-Wilson E, Campbell KJ, Laws RA. Factors influencing engagement and behavioral determinants of infant feeding in an mHealth program: qualitative evaluation of the growing healthy program. JMIR Mhealth Uhealth 2017;5(12):e196. [Medline: 29254908]

44. Taki S, Lymer S, Russell CG, Campbell K, Laws R, Ong KL, et al. Assessing user engagement of an mHealth intervention: development and implementation of the growing healthy app engagement index. JMIR Mhealth Uhealth 2017 Jun 29;5(6):e89 [FREE Full text] [doi: 10.2196/mhealth.7236] [Medline: 28663164] 
45. Roll C, Cheater F. Expectant parents' views of factors influencing infant feeding decisions in the antenatal period: a systematic review. Int J Nurs Stud 2016 Aug;60:145-155. [doi: 10.1016/j.ijnurstu.2016.04.011] [Medline: 27297376]

46. Zarnowiecki D, Ball K, Parletta N, Dollman J. Describing socioeconomic gradients in children's diets - does the socioeconomic indicator used matter? Int J Behav Nutr Phys Act 2014 Mar 28;11(1):44 [FREE Full text] [doi: 10.1186/1479-5868-11-44] [Medline: 24674231]

47. Australian Bureau of Statistics. 2017. 6227.0 - Education and Work, Australia, May 2017 URL: http://www.abs.gov.au/ ausstats/abs@.nsf/mf/6227.0[WebCite Cache ID 6xW5ym1SP]

48. Campbell KJ, Lioret S, McNaughton SA, Crawford DA, Salmon J, Ball K, et al. A parent-focused intervention to reduce infant obesity risk behaviors: a randomized trial. Pediatrics 2013 Apr;131(4):652-660 [FREE Full text] [doi: 10.1542/peds.2012-2576] [Medline: 23460688]

49. Daniels LA, Mallan KM, Battistutta D, Nicholson JM, Perry R, Magarey A. Evaluation of an intervention to promote protective infant feeding practices to prevent childhood obesity: outcomes of the NOURISH RCT at 14 months of age and 6 months post the first of two intervention modules. Int J Obes (Lond) 2012 Oct;36(10):1292-1298. [doi: 10.1038/ijo.2012.96] [Medline: 22710926]

50. Wen LM, Baur LA, Simpson JM, Rissel C, Wardle K, Flood VM. Effectiveness of home based early intervention on children's BMI at age 2: randomised controlled trial. BMJ 2012;344:e3732. [doi: 10.1136/bmj.e3732]

51. Campbell KJ, Hesketh KD, McNaughton SA, Ball K, McCallum Z, Lynch J, et al. The extended Infant Feeding, Activity and Nutrition Trial (InFANT Extend) Program: a cluster-randomized controlled trial of an early intervention to prevent childhood obesity. BMC Public Health 2016;16:166. [doi: 10.1186/s12889-016-2836-0]

52. Horodynski MA, Silk K, Hsieh G, Hoffman A, Robson M. Tools for teen moms to reduce infant obesity: a randomized clinical trial. BMC Public Health 2015 Jan 21;15:22 [FREE Full text] [doi: 10.1186/s12889-015-1345-x] [Medline: 25604090]

53. Uesugi KH, Dattilo AM, Black MM, Saavedra JM. Design of a digital-based, multicomponent nutrition guidance system for prevention of early childhood obesity. J Obes 2016;2016:5067421 [FREE Full text] [doi: 10.1155/2016/5067421] [Medline: 27635257]

54. Wen LM. Obesity in young children: what can we do about? J Obes Weight Loss Ther 2015;5(6):286. [doi: 10.4172/2165-7904.1000286]

55. Lau Y, Htun TP, Tam WS, Klainin-Yobas P. Efficacy of e-technologies in improving breastfeeding outcomes among perinatal women: a meta-analysis. Matern Child Nutr 2016 Dec;12(3):381-401. [doi: 10.1111/mcn.12202] [Medline: 26194599]

56. Jiang H, Li M, Wen LM, Hu Q, Yang D, He G, et al. Effect of short message service on infant feeding practice: findings from a community-based study in Shanghai, China. JAMA Pediatr 2014;168(5):471-478. [doi: 10.1001/jamapediatrics.2014.58] [Medline: 24639004]

\section{Abbreviations \\ AOR: adjusted odds ratio \\ BFF: Baby's First Food \\ BMI: body mass index \\ GH: Growing healthy \\ SMS: short message service}

Edited by G Eysenbach; submitted 26.09.17; peer-reviewed by K Skelton, G Peterson; comments to author 26.10.17; revised version
received 04.12.17; accepted 07.12.17; published 19.04.18
Please cite as:
Laws RA, Denney-Wilson EA, Taki S, Russell CG, Zheng M, Litterbach EK, Ong KL, Lymer SJ, Elliott R, Campbell KJ
Key Lessons and Impact of the Growing Healthy mHealth Program on Milk Feeding, Timing of Introduction of Solids, and Infant
Growth: Quasi-Experimental Study
JMIR Mhealth Uhealth 2018;6(4):e78
URL: $\underline{\text { http://mhealth.jmir.org/2018/4/e78/ }}$
doi: $10.2196 /$ mhealth.9040
PMID: $\underline{29674313}$

(CRachel A Laws, Elizabeth A Denney-Wilson, Sarah Taki, Catherine G Russell, Miaobing Zheng, Eloise-Kate Litterbach, Kok-Leong Ong, Sharyn J Lymer, Rosalind Elliott, Karen J Campbell. Originally published in JMIR Mhealth and Uhealth (http://mhealth.jmir.org), 19.04.2018. This is an open-access article distributed under the terms of the Creative Commons Attribution License (https://creativecommons.org/licenses/by/4.0/), which permits unrestricted use, distribution, and reproduction in any 
medium, provided the original work, first published in JMIR mhealth and uhealth, is properly cited. The complete bibliographic information, a link to the original publication on http://mhealth.jmir.org/, as well as this copyright and license information must be included. 